\section{INTERNATIONAL BULLETIN OF BACTERIOLOGICAL NOMENCLATURE AND TAXONOMY \\ Volume 8 No. $2 \quad$ April 15, 1958}

pp. 97-109

\title{
MICROBIOLOGICAL TAXA OF INFRASPEC IFIC AND INFRASUBSPECIFIC RANK
}

\author{
R.E. Buchanan \\ Department of Bacteriology \\ Iowa State College, Ames
}

Microbiology, more particularly bacteriology, in common with all of biology, is confronted with the important problem of fixing upon a satisfactory method of naming taxa (taxonomic groups) below the rank of species. There are many such groups that have become of major economic and scientific importance, their names are frequently without adequate integration into the generally recognized nomenclatural codes. One example from bacteriology may be noted.

Quite satisfactory techniques have been developed for distinguishing and characterizing the several hundred strains of bacteria assignable to the genus (or group) Salmonella. Most of these strains are of sufficient importance in epidemiology that they should be named. Methods of labeling and cataloguing them have been developed, in large part due to the good work of the International Subcommittee on Enterobacteriaceae and to the establishment of laboratories to serve as "typing centers" primarily to serve the needs of epidemiologists. The practical question arises, are these groups of cultures, these differentiable strains of bacteria, to be regarded as taxa (taxonomic groups) in bacteriological nomenclature? Should they be included in the category of taxa that are being recognized as of lower rank than species or subspecies and that are now commonly designated (following the proposal of the zoologists) as of "infrasubspecific" rank? Are they "taxa"?

What is a taxon? The question has been quite satisfactorily answered from the standpoint of botany by Rickett (1958). He analyzes with some care the meaning of "taxon" and defines it as follows:

\footnotetext{
". - a taxon is not an abstraction, nor does it include the categories of taxonomic thought. It is a taxonomic group or assemblage of plants or animals, having certain characteristics in common which we take as evidence of
} 
genetic relationship, and possessed of some degree of objective reality. We can use the word wherever we can use 'taxonomic group' in referring to the characteristics, dynamics, distribution, or uses of such an assemblage."

This definition definitely includes as taxa all the infraspecific groups of the botanists and the infrasubspecific groups of the zoologists. The codes of nomenclature in all three branches of biology recognize taxa of the rank of subspecies, and all recognize more or less definitely taxa of rank lower than subspecies, though no two are in exact agreement as to the manner in which these groups are to be treated from the standpoint of taxonomy.

The three International Codes of Nomenclature may be classified from the standpoint of treatment of infraspecific and infrasubspecific taxa as follows:

A. Codes which recognize the coordinate status of the names of species and of subspecies.

1. Code which recognizes as valid (legitimate) only those names of infrasubspecific forms which are Latin or Latinized. . . . . . . . . . - Internationa l Code of Zoological Nomenclature

2. Code which recognizes as legitimate (valid) both names of infrasubspecific forms which are Latin or Latinized and those which are neither (vernacular names, formulae, etc.) .......... - International Code of Nomenclature of Bacteria and Viruses

B. Code which does not recognize the coordinate nomenclatural status of names of species and subspecies. Two codes have been developed and recognized, distinguished by their different treatment of infrasubspecific forms.

1. Code that provides for Latin or Latinized names of infraspecific taxa to be applied to plants in nature (wild plants)................

- International Code of Botanical Nomenclature 
2. Code that provides for names of infrasubspecific taxa to be applied to cultivated plants; these names are not Latin or Latinized. . . . . . . . . - Internationa I_Code of Nomenc lature for Cultivated

Plants

\section{Treatment of Infrasubspecific Names in Zoology}

The International Code of Zoological Nomenclature places the names of taxa that are recognized into four groups based upon the number of words in a name. The names of subgenera and all higher taxa have one word, they are "uninominal"; the "designation" of a species has two words, is "binominal"; the "designation" of a subspecies has three words, is "trinominal"; the "name" of an infrasubspecific form when cited in relation to a species is "qualifiedly trinominal" in that there is interpolated after the specific name (specific epithet) a word indicating the status of the infrasubspecific form; the "scientific designation" of an infrasubspecific form cited in relation to a subspecies is "qualifiedly quadrinominal." In general, the rules that apply to specific and subspecific names are also applicable to the names of infrasubspecific forms, except that laws of Priority and Homonymy are to be applied "independently to the two classes: (1) specific and subspecific names and (2) infrasubspecific names."

The glossary of the Zoological Code defines an infrasubspecific form as any form of a species that is not to be considered a subspecies, such as different sexual forms, transition forms and all other minority forms but not including "aberrations." The examples given are "the dwarf first spring generation workers of bumble-bees; the worker major, the worker minor, the soldier castes of many species of ants."

The rule for citation of an infrasubspecific name resembles that for the citation of the name of a species, it consists of the binomen of the species or subspecies name followed by a comma and "an expression indicating the status attributed" to the form in question (e.g.: "form vern."?" or "ab"), this in turn followed by the name (epithet) of the infrasubspecific form and the name of the author. The example given is "Rana esculenta marmorata, ab. ㄸ-us Black." 
It is not clear whether it is the intent that this provision by the zoologists for recognition of infrasubspecific forms extends to the naming of strains of mutants as in Drosophila, or to the breeds of domestic animals and birds. Certainly there is no acceptance of vernacular names as names for infrasubspecific forms that have arisen under "cultivation." This is in marked contrast to the recognition of "fancy" names for cultivated plants as noted later.

Nor are there suggestions that parasitic forms showing little or no morphological differences but having marked host preferences should be named on the basis of the host affected.

Ireatment of Infraspecific and Inf rasubspecific Names in Botany

The Botanical Code differs from those of Zoology and of Bacteriology in recognition of a larger number of consecutively subordinate ranks, beginning with the species. They a re Species, Subspecies, Variety (Varietas), Subvariety (Subvarietas), Form (Forma), and Subform (Subforma). All ranks of taxa below species are placed under the genrral heading of "infraspecific," there is no recognition of the zoological term infrasubspecific, although varieties, subvarieties, forms, and subforms may be regarded as included in this category.

An example of the full name of an infraspecific taxon in the genus Saxifraga is given as Saxifraga aizoon subvar. brevifolia forma multicaulis subforma surculosa Engler and Imscher.

The epithets used for subspecies and varieties are formed as are those of species. These epithets follow in order with the epithets of the highest rank first. The epithets of subvarieties and forms are similarly constructed, although there is provision that for the latter numbers or letters may be used to "facilitate their arrangement." A binary combination consisting of the name of the genus followed by the epithet of an infraspecific taxon is illegitimate, but a ternary combination consisting of the binary combination forming the name of a species followed by the epithet of the infraspecific taxon is legitimate providing 
the rank of the infraspecific taxon is stated. The same epithet may be used for "infraspecific taxa within different species, even species of the same genus." In general, "two infraspecific taxa within the same species, even if they are of different rank, cannot bear the same infraspecific epithet unless their names are based upon the same type." The infraspecific names under this code are in general applied to wild plants, although plants brought into cultivation from the wild which differ in no fundamental way from the parent wild stocks bear the same names as are applied to the same infraspecific taxa in nature.

However, plants that arise "in cultivation through hybridization, mutation, or other processes which tend to establish recognizable differences from the parent stocks receive epithets, preferably in common language (i.e., fancy epithets), markedly different from the Latin epithets of species or varieties." For these an "International Code of Nomenclature for Cultivated Plants" has been formulated and adopted by the International Commission for the Nomenclature of Cultivated Plants of the International Union of Biological Sciences. The Commission charged with the development of this Code of Nomenclature for Cultivated Plants included three groups of members, one group representing agriculture, a second forestry, and a third horticulture. This Code states that it is important "that a precise, stable, and internationally accepted system should be available "for naming of cultivated plants." It makes clear that "the International Code of Botanical Nomenclature governs the use of scientific ("Latin") names for both cultivated and wild plants." The purpose of the Code is "to promote uniformity, accuracy, and fixity in the naming of agricultural, silvicultural, and horticultural cultivars (varieties) which are normally given fancy names," such as "the rose Peace." The common names (vernacular names) which are applied to genera and species such as "potato," "rye," "sweet cherry" are not regulated by this Code.

The Code authorizes the use of the term "cultivar" as interchangeable with the term "variety" as commonlyapplied to cultivated plants. Cultivar is defined as "an assemblage of cultivated individuals which are distinguished by any characters (morphological, physiological, cytological, chemical, or others) significant for the purposes of agriculture, 
forestry, or horticulture, and which, when reproduced (sexually or asexually), retain their distinguishing features." There is insistence that "Registration of cultivar (variety) names is of the greatest importance for nomenclatural stability)." A distinction is drawn between the use of the term "variety" as used in this code and the term "varietas" as used in the International Bacteriological Code.

A cultivar may be any one of several kinds of unit:

a) A clone (cl.), defined as "consisting of uniform material derived from a single individual and propagated entirely by vegetative means," as by cuttings, grafts, etc.

b) A line, "consisting of a sexually reproducing population of uniform appearance, propagated by seeds or by spores, its stability maintained by selection to a standard."

c) "An assemblage of individuals (reproducing sexually or by apomixis) showing genetical differences but having one or more characteristics by which it can be differentiated from other cultivars (varieties)." As Medicago sativa 'Ranger'.

d) A uniform group which is a first generation hybrid $\left(F_{1}\right)$ reconstituted on each occasion by crossing two or more breeding stocks maintained either by inbreeding or by clones. As maize US.13.

The designation of an improved selection of a cultivar by the use of the term "strain" is rejected. However, the use of the term "group" is authorized: "Within a species or interspecific hybrid which includes many cultivars (varieties), assemblages of similar cultivars (varieties) may be designated as groups."

The names of a cultivar given after 1 January 1959 must be a "fancy name," that is, one markedly different from a scientific name of Latin form. A cultivar name "directly attached to a scientific or common name, must be distinguished either by placing the abbreviation $\underline{\underline{c}} \underline{\text {. before }} i t$, or typographically, as by enclosing it within single quotation marks." 
Capital initial letters must be used for all words of a new cultivar name. The name of a cultivar must be attached directly or by implication "either to a scientific name or to a common name of the plant concerned, provided the common name is unambiguous." The name of a cultivar should consist preferably of one or two words, never more than three, with any symbol, letter or numeral crunted as a word. Rules are laid down for the rejection of inadmissible names, for publication priority, and for rejection of names. The importance of registration of all cultivar names is emphasized and a list of the several organizations that have been set up for the registration of cultivar names in various fields is given. There is also an appendix which lists recommendations for the guidance of registration authorities.

Some botanists believe the International Code of Nomenclature for Cultivated plants in some cases to be too narrow in its coverage. Hegnauer reports that in 1957 there was held in Wageningen, Holland, an International "Arbeitstagung über Arznei- und Nutzpflanzenforschung." Here it was proposed that the Code for cultivated plants be extended to cover the naming of wild plants showing no noteworthy morphological differences but distinguished by their production of chemicals of economic significance, often important from the standpoint of pharmacology. It was suggested that "chemical races" be recognized, the term "race" being used in the sense of an infraspecific related group. At this conference Tetenyi proposed that for designation of such races the prefix "chemo-" be used. Later (1958) he published an elaborated proposal for a supplementary nomenclature adapted to the expression of physiological-chemical phenomena, to the naming of "natural" as well as "artificial" races, to polyploids, to races morphologically alike but differing in the amount of the active material produced. The needs of botanists, chemists, horticulturists, and "selectionneurs" should be met. He proposed the recognition of several infraspecific categories for cultivated plants; chemoconvar (chcon.), chemocultigrex (chg.), and chemocultivar (chvv.). For plants growing wild in nature which show "spontaneous" differences he proposes the categories chemovar (chvar.) and chemoforma (chf.) For example, he would distinguish six chemical races of Cinnamomum camphora Sieb. subsp. formosana Hirota by naming them respectively chvar. borneol; chvar. campher; chvar. cineol; chvar. linalool; chvar. safrol; and chvar. sesquiterpen. He would recognize 
two chemoformae in the chvar. lina lool as chf. 86 per cent and chf. 71 per cent. In the cultivated Cinchona ledgeriana Moens two chemocultigreges would be named, chg chinidin and chg. cinchonidin.

Mansfield (1958) also notes the need for distinguishing plants on the basis of physiological characteristics, particularly those sibs that show no morphological differences. He states that Hegnauer has proposed the use of the term forma biochimica to correspond to the recognized forma specialis, and suggests that these terms are not very suitable as they consist of two words. He opposes the use of the term type as an infraspecific designation as it already has a definite meaning both in nomenclature and in morphology. He proposes the use of the term isovar (from isovarietas) for a physiological race as contrasted to varietas for a morphological race.

Lanjouw (1958) proposes that the separation between names of wild plants and those of cultivated plants be maintained, that "chemical strains or varieties formed in the wild should be treated as ordinary infraspecific units, they should be named, and the publication of the name should be accompanied by a Latin diagnosis." To follow this suggestion of Latinization of all the names of wild infraspecific plants distinguished on the bases of physiological and bi $\propto$ hemical differences would involve very much practical difficulty. In the Latin descriptions many chemical compounds would need to be Latinized and declension and gender determined. The epithets of the infraspecific units might well appear in such forms as Cinnamomum camphora Sieb. subsp. formosana forma sesquiterpenificum (or var. linalooligenum).

Lanjouw would treat those strains that have been developed in the course of cultivation as "cultivars" to be given "fancy" names as prescribed in the International Code of Nomenclature for Cultivated Plants. Two difficulties at least would need to be resolved. A cultivated plant distinguished from others of the same species by the production of some definite chemical compound is not quite in the same category as a garden vegetable, a "fancy name" is not very suitable; one would hesitate to name a cultivar of a plant economically important as producing borneol as "cultivar 'Jones' Best'." Further, the several wild races of a species producing 
different but related chemicals of economic significance would commonly be brought under cultivation, and new mutants or lines or clones developed under cultivation would have a different set of rules governing their naming than would the several strains first found wild. This could readily lead to confusion. However, Lanjouw concludes that these chemical (biochemical) and pharmaceutical characters need to be recognized and treated formally as they may prove to be of real value in taxonomy.

\section{Treatiment of Infraspecific and Infrasubspecific} Names in Bacteriology

The Rules of the International Code of Nomenclature of the Bacteria and Viruses resemble those of Zoology in that specific and subspecific epithets (the specific and subspecific names of the zoologists) are coordinate nomenclaturally. Provision is also made for the recognition of taxa of infrasubspecific rank. The Bacteriological Rules differ from those of Zoology in that under appropriate circumstances either Latinized or vernacular words or formulae or other designations may be used as infrasubspecific epithets. Further, the Bacteriological Code makes provision for infrasubspecific names under the heading of "Recommendations" rather than "Rules." In Bacteriology there is not the distinct separation of the nomenclature of infrasubspecific forms that are found "wild" and that "are developed under cultivation," distinctions to be found in the two Botanical Codes. Further, in bacteriology infrasubspecific epithets may be either Latinized or vernacular or given as formulae.

A careful study should be made of the status of the names given to the infrasubspecific forms in Bacteriology by the Judicial Commission and the International Committee on Bacteriological Nomenclature at the Stockholm (1958) meeting. It is believed that there has been sufficient accumulation of basic data to permit the formulation of rules which wald go far in the elimination of what seems to be unnecessary confusion in the nomenclature of so many strains of bacteria that are of pharmaceutical, medical, sanitary, technical, analytical, biochemical, genetic, antibiotic, physiological, or other importance. The need for agreement upon suitable rules for the naming of these strains is even more pressing than in the many other fields of biology. 
Several categories of infraspecific epithets are recognized in the Bacteriological Code. Their definitions and uses should be appraised before an attempt is made to develop logical amendments to the Code that would seem to fit the peculiar needs of bacteriology. It is, of course, unfortunate that the three areas of biology should not have arrived at some greater degree of agreement in this rapidly developing field of biological nomenclature. Quite possibly the reconciliation of the three divergent approaches to the nomenclature of the infrasubspecific forms may be a matter that should be taken under advisement by the International Union of Biological sciences. This organization in a sense has sponsored the recent revisions of all three codes of biological nomenclature, and might well take note of the impending chaos in what is essentially popular nomenclature because of the lack of coordination among the several Codes. A study of the problem from the standpoint of biology as a whole rather than from the points of view of the three divisions is desirable.

The terms commonly used to designate the rank of the infrasubspecific taxa in bacteriology are strain, biotype, serotype, phagotype, morphotype, group, phase, forma specialis, stage, and state. Consideration should also be given to better differentiation of races or strains of bacteria that are important because they produce different chemical compounds or substances of pharmaceutical significance such as antibiotics, likewise those that as the result of mutation have lost the ability to synthesize certain needed nutrients, and which have oecome important in qualitative and quantitative analyses for these compounds.

The Bacteriological Code states that subdivisions of species (other than subspecies) and subdivisions of subspecies are to be given names (better, epithets) to follow the name of the species or subspecies. These epithets may be words in the vernacular or in Latin or words in Latinized form, or they may be names of persons or of places; they may be letters or numerals separately or combined into descriptive formulae, or they may be numbers or other designations used by Type Culture Collections to identify the different strains ma intained.

It is proposed that the Recommendations that now govern 
the use of infrasubspecific names and epithets be modified where advisable into Rules and emended Recommendations. It is suggested that "Rule 8 Infrasubspecific Subdivisions" be emended to make mandatory certain treatments of the names of infrasubspecific taxa. The following suggestions are wholly tentative and intended to assist the members of the Judicial Commission and the International Committee on Bacteriological Nomenclature at their meetings at the Stockholm (1958) Congress.

1. The terms used to designate the rank of the several infrasubspecific taxa in bacteriology should be evaluated and more accurately defined. The terms listed in the International Code of Nomenclature and Taxonomy are strain, type, biotype, serotype, phagotype, morphotype, group, phase, forma specialis, stage, and state. Are all these terms needed? The terminology of the International Code of Nomenclature for Cultivated Plants should be studied for suggestions as to possible useful adaptations to bacteriology. Such designations as cultivar, chemovar, chemocultivar, chemoforma may have useful implications in some bacterial taxa.

2. Infrasubspecific nomenclature has already been used more or less extensively in certain genera and families of bacteria. To what extent is it desirable or necessaryto fix the terms used for designating the infrasubspecific ranks? In some cases within a single species several infrasubspecific groupingshave been used. One may group the strains of Staphylococcus on the basis of bacteriophage susceptibility (i.e., as phagotypes), or on the bas is of virulence, or on the basis of serology (i.e. as serotypes). The same strain may bear more than one infrasubspecific name. If such duplicate cataloguing is desirable (probably it is) the implications should be clear.

3. National and international committees involved in studies of special groups of bacteria (usually of genera or families), perhaps specialists in particular groups, might well develop proposals for the standardization of the designation of names of infrasubspecific categories. Among the genera and other taxa that might receive consideration are the following: 
Page 108

I N T E R N A T I O N A L BULLET I N

Pseudomonas. To what extent might use of inf rasubspec ific names be used for host preference, virulence, phage susceptibility, pigment production, etc.

Xanthomonas. Host preferences, etc.

Acetobacter. Chemical final products, morphotypes.

Vibrio. Serotypes, etc.

Rhizobium. Forma speciales (host preferences), phagotypes, virulence.

Escherichia. Biotypes, serotypes, phases, phagotypes, virulence, etc. Similarly for the other genera of Enterobacteriaceae; Aerobacter, Klebsiella, Serratia, Proteus, Sa lmonella, Shigella.

Pasteurella. Biotypes, host specificity, serotypes, etc.

Micrococcus and Staphylococcus. Biotypes, serotypes, virulence, phagotypes.

Neisseria. Biotypes, serotypes, etc.

Diplococcus. Biotypes, serotypes, etc.

Streptococcus. Biotypes, serotypes, virulence, phagotypes, etc.

Lactobacillus. Biotypes, serotypes, etc.

Propionibacterium. Biotypes.

Corynebacterium. Biotypes, phagotypes, morphotypes, etc.

Bacillus. Morphotypes, biotypes, phagotypes, etc.

Clostridium. Morphotypes, biotypes, phagotypes, etc.

The several genera of the Mycobacterlaceae, Actinomycetaceae, and Streptomycetaceae: Mycobacterium, Nocardia, Actinomyces, Streptomyces, Micromorospora, Morphotypes, virulence, serotypes, antibiotic production, phagotypes, etc. 
Ireponema. Morphotypes, host specificity, serotypes, etc.

Leptospira. Serotypes, host specificity.

Rickettsia. Host specificity, vector specificity, serotypes.

\section{REFERENCES}

Bradley, J. Chester. 1957. Draft of the English Text of the International Code of Zoological Nomenclature as Amended by the Paris (1948) and Copenhagen (1953) Congresses. Bull. Zool. Nomen. 14:31-285.

Editorial Committee of the Commission. 1958. International Code of Nomenclature for the Nomenclature of Cultivated Plants. International Bureau for Plant Taxonomy and Nomenclature of the International Association for Plant Taxonomy. Utrecht, Netherlands. Regnum Vegetabile 10; $1-28$.

Editorial Committee, J. Lanjouw, Chairman. 1956. International Code of Botanical Nomenclature. International Bureau for Plant Taxonomy and Nomenclature of the International Association of Plant Taxonomy. Utrecht, Netherlands.

Hegnauer, R. 1958. Zur Nomenklatur chemischer Sippen. Taxon 7:39-40.

Lanjouw, J. 1958. On the nomenclature of chemical strains. Taxon $7: 43-44$.

Mansfield, R. 1958. Zur Frage der Behandlung nur physiologisch, aber nicht morphologisch verschiedener Sippen in der botanischen Systematik. Taxon 7:41-43.

Rickett. H.W. 1958. So what is a taxon? Taxon 7:37-38.

Tetenyi, Pierre. 1958. Proposition à propos de la nomenclature des races chimiques. Taxon 7:40-41. 
